\title{
Automation in Fire Safety Engineering Using BIM and Generative Design
}

\author{
Ruggiero Lovreglio*, School of Built Environment, Massey University, \\ Palmerston North, New Zealand \\ Pete Thompson, Autodesk Inc, Boston, MA, USA \\ Zhenan Feng, School of Built Environment, Massey University, Palmerston \\ North, New Zealand
}

Accepted: 2 July 2021/Published online: 19 July 2021

\section{Dear Editor,}

Building Information Modelling (BIM) is a modern technology and process that has had a dramatic impact on the Architecture, Engineering and Construction (AEC) industry over the last decade [1]. The latest statistics show that at least 18 countries around the world are mandating BIM for use in public projects, and this enforcement of BIM adoption continues to proliferate in other countries around the world [2, 3]; with different governments sometimes using different strategies to incentivise the use of BIM in the AEC industry [4]. Also, BIM is becoming an integral part of the design process, right from the conceptual stage - where project stakeholders can leverage different Levels of Development for BIM projects (i.e. from LOD 100 to LOD 500) [5]. This integration of design modelling and analysis from the beginning of a project can streamline coordination, communication, and collaboration. "BIM has enabled dramatic changes in the processes for designing and building" in the AEC industry [1] where the datarich model is an ideal platform for analysis through the project lifecycle, utilised by structural engineers, services engineers, energy modellers, but rarely Fire Safety Engineers who have often been much slower to adopt BIM than the rest of the AEC sector and usually only become involved in the later design stages.

BIM is now becoming a critical subject for the Fire Safety Engineering (FSE) community to consider. Different studies have shown that FSE has been slow to embrace digital technologies [6,7]. One of the main obstacles is that interoperability issues have sometimes occurred between BIM platforms and FSE computational tools (i.e., fire and evacuation simulation software tools) [8]. However, different FSE computational fire engineering tools are now capable of importing

\footnotetext{
* Correspondence should be addressed to: Ruggiero Lovreglio, E-mail: r.lovreglio@massey.ac.nz
} 
the IFC format (BIM files) to define the geometry under analysis. Also, basic features for fire safety engineering and occupant movement are becoming available as integral parts of popular BIM platforms, such as Autodesk Revit's Path of Travel [9] and Social Distancing Toolkit [10].

To date, the fire safety scientific community has been slow to leverage the potential for integrating analytical "add-ins" or plug-ins for BIM-platforms, enabling fire safety engineering workflows directly within the BIM platform [11]. Rahouti et al. [12] showed that BIM can be a critical component while designing virtual reality training tools for fire safety. Other research has shown how IFC can be used to transfer and share building data with FSE computational tools [8, 13-15] or to verify if a construction project is compliant with a defined fire safety code [16]. However, the literature does not provide any application or discussion on the potential use of one of the most advanced features of BIM: parametric modelling. Parametric modelling allows building objects to be represented by implementing parameters and rules that automatically define the geometry and optionally nongeometric properties, features, and behaviours [1]. Parametric modelling allows a building to be described in a computer-friendly coding system to enable users to automate the creation of multiple alternate building designs using Generative Design (GD) techniques.

GD is a way of rapidly exploring design possibilities or optimisations by combining algorithms with parametric modelling [17]. GD can assist FSE designers by generating and comparing tens, hundreds or thousands of possible designs and select the one which meets specific fire safety criteria, client expectations, and code requirements. According to Vermeulen and El Ayoubi [18], GD can be conceptualised in the following steps:

1. Parameter Inputs. In this step, designers identify the parameters of BIM models that can be modified to generate different design solutions and in which ranges these parameters can vary. These ranges can be defined in accordance with existing fire safety regulations (e.g., the minimum number of exits and minimum exit sizes) or current fire systems available on the market (e.g., sprinklers specifications).

2. Design Goals. In this step, designers need to specify multiple criteria to identify the optimal design solutions. For instance, one of the possible fire safety criteria could be the maximisation of the difference between the Available Safe Egress Time and Required Safe Egress Time (i.e., max ASET-RSET). Other practical possible criteria could be costs and construction times. It is worth highlighting that some criteria can potentially conflict with each other.

3. Design Optimisation. In this step, different design solutions are generated to identify the optimal design solutions. The search for the optimal design solution can be achieved by generating all possible solutions (i.e., full factorial approach), using generative scripts from FSE rules, random design variations, or algorithms (e.g. genetic algorithms) to assess and prioritise the optimal solutions [19]. The algorithms implement generative systems to analyse, rank, and evolve designs as explained in the following iterative sub-steps: 
a. Generate multiple design solutions using initial parametric ranges and conditions for the first iteration and the parameters identified in the sub-step ' $d$ ' for the following iterations.

b. Analyse the design solutions using the goals defined in 2. In this sub-step, the generated design solutions need to be analysed using FSE computational tools with the inputs from designers and generated design solutions (e.g., generated geometric floor plans). For instance, in the case of maximisation of the difference between ASET and RSET, it is necessary to use both evacuation and fire models to quantify both times for each design solution.

c. Rank the design solutions based on results from sub-step ' $b$ '. The ranking of the design solutions can be challenging, especially when there are conflicting criteria such as the number of exits and costs. Using standard multi-objective optimisations, it is possible to identify which design solutions are optimal or dominant [19]. At this stage, the optimisation can be stopped to provide the result to designers for the "Design Exploration" stage 4 or the optimisation can proceed with another iteration by executing sub-step ' $d$ '.

d. Evolve the design based on the best solutions. In this step, the best solutions identified in sub-step ' $c$ ' are used to define a new set of parameters to use in sub-step 'a', which can lead to the identification of the optimal solutions.

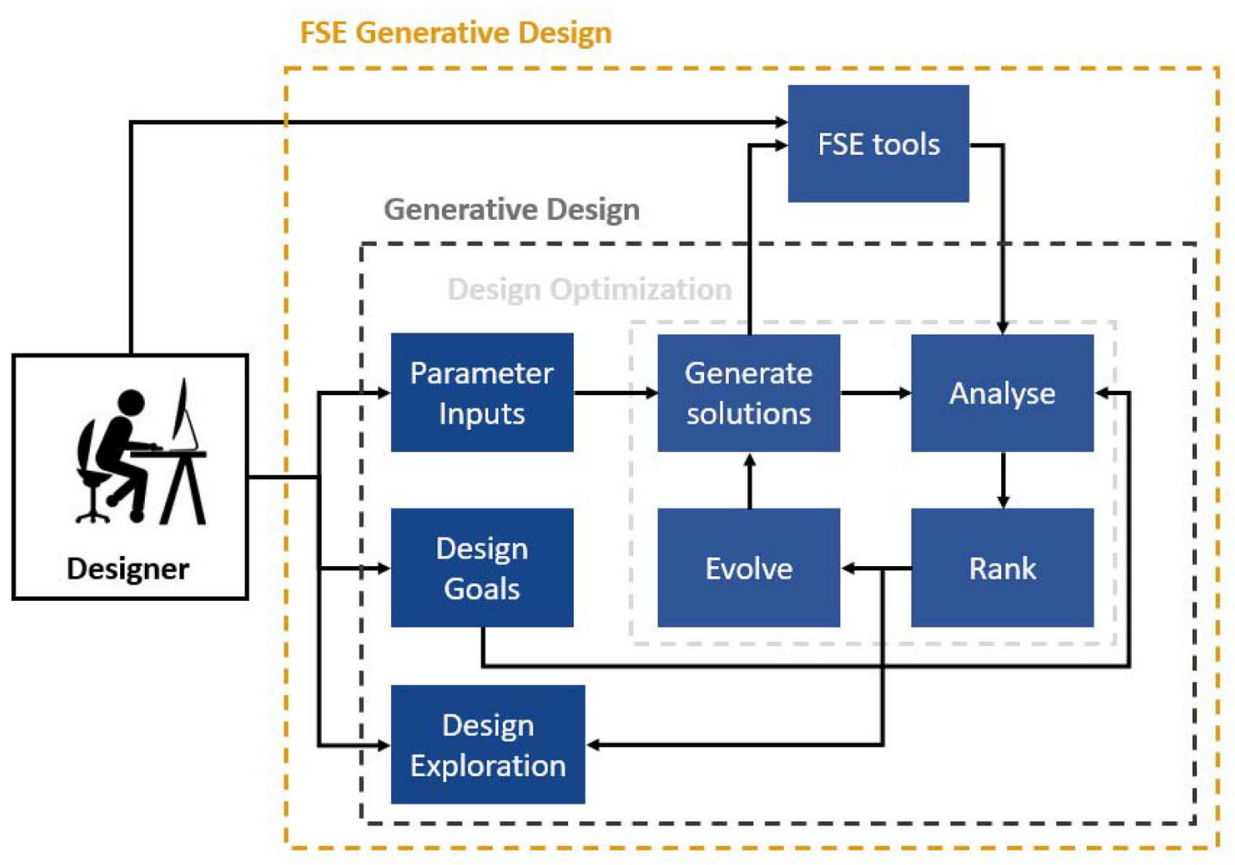

Figure 1. Generative design for Fire Safely Engineering (FSE). 
4. Design Exploration. In this stage, designers can select the best design solutions identified in the multiple iterations from the optimal solutions now available for review.

These steps are visualised in Fig. 1, which also shows the designers' involvement and intervention in the automated process. GD is available at all stages of BIM projects, with more parametric freedom in initial design stages. The application of GD for FSE needs to account for the computational expense that be required by some fire engineering tools, such as Computational Fluid Dynamic simulation packages. In these cases, FSE designers might use a pragmatic approach to select the number of parameters to change in Step 1 and the total number of design variations. A possible solution to tackle this limitation is to use cloud-based FSE platforms which can allow the simulation of hundreds of design variations in short time periods.

In conclusion, GD has a lot of potentials and can provide FSE designers with a new generation of instruments that can assist them in investigating multiple design solutions in a controlled and automated way. The number of generated designs can be limited for computationally expensive processes and carefully controlled by designers if required, especially if cloud-compute resources are available to run multiple assessments in parallel. The benefits and limitations of GD for FSE still need to be fully investigated by the fire safety scientific community, but to date, the level of adoption has been minimal, and the profession is missing out on new, rapid workflows, which in themselves could awaken an era "new generation" of sophisticated, but more efficient designs available to the community.

\section{References}

1. Sacks R, Eastman C, Lee G, Teicholz P (2018) BIM handbook: A guide to building information modeling for owners, designers, engineers, contractors, and facility managers. Wiley, New York

2. Paul S (2018) BIM adoption around the world: how good are we? - Geospatial World, https://Www.Geospatialworld.Net/Article/Bim-Adoption-around-the-World-How-Good-AreWe/. (2018). https://www.geospatialworld.net/article/bim-adoption-around-the-world-howgood-are-we/ (Accessed June 10, 2021)

3. Miró JM (2021) In which countries is BIM mandatory for public projects? - ArchDaily, https:/Www.Archdaily.Com/956398/in-Which-Countries-Is-Bim-Mandatory-for-Public-

Projects. https://www.archdaily.com/956398/in-which-countries-is-bim-mandatory-forpublic-projects (Accessed June 10, 2021)

4. Kassem M, Succar B (2017) Macro BIM adoption: comparative market analysis. Autom Constr 81:286-299. https://doi.org/10.1016/j.autcon.2017.04.005

5. BAC Committee, Appendix C-The NZ BIM Handbook (2019)

6. Chevin D (2020) The New Fire Safety Digital Framework Explained, https://www. Bimplus.Co.Uk/Explainers/New-Fire-Safety-Digital-Framework-Explained/

7. Lovreglio R, Ronchi E, Kinsey MJ (2019) An online survey of pedestrian evacuation model usage and users. Fire Technol 56:1133-1153. https://doi.org/10.1007/s10694-01900923-8 
8. Siddiqui AA, Ewer JA, Lawrence PJ, Galea ER, Frost IR (2021) Building Information Modelling for performance-based Fire Safety Engineering analysis - a strategy for data sharing. J Build Eng, 102794. https://doi.org/10.1016/J.JOBE.2021.102794

9. Hanson J (2020) Have you tried? Revit Path of Travel Tool. https://Blogs.Autodesk. Com/Revit/2020/02/18/Revits-Path-of-Travel-Tool-Makes-for-Quick-and-Easy-Egress/. https://blogs.autodesk.com/revit/2020/02/18/revits-path-of-travel-tool-makes-for-quickand-easy-egress/ (Accessed June 10, 2021)

10. Thompson P, Wang M (2020) Using Revit to Design for Social Distancing: New Tools and How to Use Them - Autodesk University, https://www.Autodesk.Com/AutodeskUniversity/Class/Using-Revit-Design-Social-Distancing-New-Tools-and-How-Use-Them2020. https://www.autodesk.com/autodesk-university/class/Using-Revit-Design-Social-DistancingNew-Tools-and-How-Use-Them-2020 (Accessed June 10, 2021)

11. Bimfire, Behind Bimfire: Fire protection as a part of the BIM process. https://Bimfire. App/News/behind-Bimfire-Fire-Protection-as-a-Part-of-the-Bim-Process/. (2020)

12. Anass Rahouti, R. Lovreglio, S. Datoussaïd, T. Descamps (2021) Prototyping and validating a Non-immersive Virtual Reality Serious Game for Healthcare Fire Safety Training. Fire Technol. https://doi.org/10.1007/s10694-021-01098-x

13. Spearpoint M (2007) Transfer of architectural data from the IFC building product model to a fire simulation software tool. J Fire Prot Eng 17:271-292. https://doi.org/ $10.1177 / 1042391507074681$

14. Dimyadi JAW, Spearpoint MJ, Amor R (2007) Generating fire dynamics simulator geometrical input using an IFC-based building information model. https://ir.canterbury.ac. nz/handle/10092/680 (Accessed June 7, 2021)

15. Dimyadi J, Solihin W, Amor R (2018) Using IFC to support enclosure fire dynamics simulation. In: Lect. Notes Comput. Sci. (Including Subser. Lect. Notes Artif. Intell. Lect. Notes Bioinformatics). Springer Verlag, Heidelberg, pp 339-360. https:/doi.org/ 10.1007/978-3-319-91638-5_19

16. Dimyadi J, Amor R, Spearpoint M (2016) Using BIM to support simulation of compliant building evacuation. CRC Press, Boca Raton. http://www.openifcmodel. (Accessed June 7, 2021)

17. Pasetti Monizza G, Bendetti C, Matt DT (2018) Parametric and Generative Design techniques in mass-production environments as effective enablers of Industry 4.0 approaches in the Building Industry. Autom Constr 92:270-285. https://doi.org/10. 1016/j.autcon.2018.02.027

18. Dieter Vermeulen, El Ayoubi M (2020) Using generative design in construction applications. https://Medium.Com/Autodesk-University/Using-Generative-Design-in-ConstructionApplications-E268c785b004

19. Rohrmann J (2019) Design optimization in early project stages a generative design approach to project development

Publisher's Note Springer Nature remains neutral with regard to jurisdictional claims in published maps and institutional affiliations. 